\title{
$\mathfrak{3} \mathfrak{i} \mathfrak{h} \mathfrak{l} \mathbf{t}$.
}

\section{Bas gewefir.}

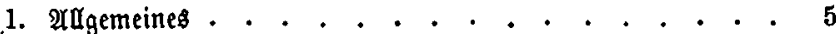

2. Die Theile des Geruehro . . . . . . . . . . . 6

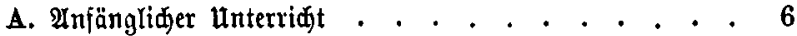

B. Eingehente Bejareifung bes Gervehrs unb jeiner Theile 9

3. Da Gerehrzubegör . . . . . . . . . . . . . 22

4. Bekandlung bes Bewehres . . . . . . . . . . . 23

A. Berlegent und Bufammenjeşent bes Berwehrs. . . . . 23

B. Reinigen und Jnftanbjeken bes Belvehr . . . . . 29

C. Befandlung bes zum Dienftgebraud abgegebenen betwefrs 34

Dite gatrone . . . . . . . . . . . . . . 38

Figur 1, ber $\mathfrak{A u f f a j}$. . . . . . . . . . . . . . 7

2, bas Befăuje. . . . . . . . . . . . . . 11

3, bas Beridłlufifüa . . . . . . . . . . . . 12

4, ber Bünbfitit unb bie Epiralfeber. . . . . . . 13

5, bie Stüb̧e. . . . . . . . . . . . . . . 14

6, ber $\mathfrak{5 a h n}$. . . . . . . . . . . . . . . 14

7, bie Stange . . . . . . . . . . . . . . 15

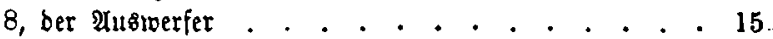

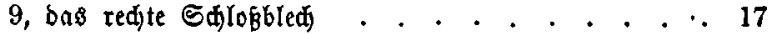

10, das linfe Sdjloßbled . . . . . . . . . . . 18

"11. bas gelabene (S)ewelgr, zum Fettern bereit (Durdjajnitt) 19

"12, zu[anmengeiektes Sd)ló (Durdjidnitt) . . . . . 20

" 13, ber rüarmärtige Theil be \&aujes . . . . . . . 9 
